\title{
BIOSSÓLIDO COMO COMPONENTE DE SUBSTRATO PARA PRODUÇÃO DE MUDAS FLORESTAIS
}

\author{
Gerhard Valkinir Cabreira ${ }^{*}$; Paulo Sérgio dos Santos Leles ${ }^{1}$; Jorge Makhlouta Alonso ${ }^{1}$; Alan Henrique Marques \\ de Abreu ${ }^{1}$; Nayara Franzini Lopes ${ }^{2}$; Gabriel Rocha dos Santos ${ }^{1}$ \\ ${ }^{1 *}$ Universidade Federal Rural do Rio de Janeiro, Seropédica, Rio de Janeiro, Brasil - gerhard_vc@ hotmail.com; pleles@ufrrj.br;
j_makh@hotmail.com; alan.abreu@cedae.com.br; grocha.santos@hotmail.com \\ ${ }^{2}$ Universidade Federal do Espírito Santo, Jerônimo Monteiro, Espírito Santo, Brasil - nayaraflopes@ hotmail.com
}

Recebido para publicação: 19/09/2015 - Aceito para publicação: 11/03/2017

\begin{abstract}
Resumo
Considerado nas cidades como resíduo sólido altamente problemático, o biossólido proveniente do lodo de esgoto é rico em matéria orgânica e nutrientes, e no Brasil sua destinação comum é o descarte em aterros sanitários. O objetivo desse trabalho foi avaliar diferentes proporções de biossólido como componente de substratos para a produção de mudas de três espécies da Floresta Atlântica, avaliando além de parâmetros morfológicos, o peso e facilidade de transporte das mudas, bem como seu crescimento em campo. O experimento foi composto por quatro tratamentos, tendo como testemunha substrato formado por esterco bovino, solo argiloso e areia, na proporção volumétrica de 40-50-10\%. Os demais tratamentos foram compostos por biossólido, solo argiloso e areia nas proporções de $20-70-10 \%, 40-50-10 \%$ e $80-10-10 \%$ respectivamente. Avaliou-se o crescimento das mudas em viveiro e sua sobrevivência e o crescimento em campo cinco meses após plantio. O biossólido tem potencial como componente de substrato para a produção de mudas florestais, consistindo em melhor destino final a este resíduo em comparação com a disposição em aterros sanitários. O uso do biossólido pode promover maior crescimento maior das mudas em viveiro, bem como diminuir o peso final das mesmas, facilitando a logística de expedição para o campo. É indicada a aplicação entre 40 a $80 \%$ de biossólido na composição do substrato. O plantio em campo demonstrou boa sobrevivência e crescimento das mudas, indicando que todos os substratos foram capazes de produzir mudas adequadas ao plantio.

Palavras-chave: Lodo de esgoto; restauração florestal; adubação orgânica; resíduos sólidos.
\end{abstract}

\begin{abstract}
Biosolid as a component of substrate for production of forest seedlings. Considered as a highly problematic solid waste, the biosolid from sewage sludge is rich in organic matter and nutrients, and in Brazil its common destination is the disposal in landfills. The objective of this paper was to evaluate different proportions of biosolid as component of the substrate for production of seedlings of three species from the Atlantic Forest, evaluating besides morphologic parameters, the weight and transport easiness of the seedlings, as well as their development in the field. The study was composed by four treatments, the control was a substrate composed by bovine manure, clay soil and sand in the volumetric proportion of 40-50-10\%. The other treatments were composed of biosolid, clay soil and sand in the proportions of $20-70-10 \%, 40-50-10 \%$ e $80-10-10 \%$ respectively. The seedlings growth in the nursery was evaluated, as also as their surviving and growth five months after plantation. The results showed great potential for using biosolids as a component of substrate for production of forest seedlings, consisting in a better destination to this residue comparing with the disposal in landfills. Biosolids can promote better growth of the seedlings in the nursery, as well as reduce their weight, easing their shipping logistic for planting. It is recommended the application of 40 to $80 \%$ of biosolid in the composition of substrate. The planting obtained good surviving and growth, showing that all substrates were capable of producing adequate seedlings for planting.

Keywords: Sewage sludge; forest restoration; solid waste; organic fertilizations.
\end{abstract}

\section{INTRODUÇÃO}

Nas últimas décadas, devido ao acelerado crescimento das cidades brasileiras, agravaram-se problemas ambientais diversos, sendo um dos mais preocupantes o manejo dos resíduos sólidos urbanos, como o proveniente do tratamento de esgoto, denominado lodo de esgoto. A destinação final desse material tem sido um grande desafio, sendo necessário e urgente, aprimorar o seu gerenciamento. Segundo Caldeira et al. (2012) na tentativa de contornar os transtornos causados pela crescente produção de lixo e outros resíduos têm-se buscado estratégias de reutilização, sendo uma das possíveis a reciclagem dessas substâncias em atividades agrícolas ou florestais. O lodo

FLORESTA, Curitiba, PR, v. 47, n. 2, p. 165 - 176, abr. / jun. 2017.

Cabreira, G. V. et al.

ISSN eletrônico 1982-4688

DOI: $10.5380 /$ rf.v47i1.44291 
de esgoto, denominado como biossólido após tratamento para estabilização, pode ser utilizado como componente de substrato para produção de mudas florestais, consistindo em alternativa sustentável de disposição final deste resíduo, podendo trazer benefícios tanto para os geradores de lodo, como para os viveiristas.

Considerando o avanço no desmatamento da Mata Atlântica, ocorrido nos séculos passados, existe a necessidade de plantios para aumento da cobertura florestal em todo o bioma. No estado do Rio de Janeiro, segundo o INEA (2015) essa demanda se manifesta por meio de vários processos administrativos que tem como medida mitigadora ou compensatória a obrigação de plantios para restauração florestal. Existe registrado junto ao órgão, área total de 12.265 hectares de compromissos de restauração, além de outros 8.637 hectares em processos pendentes. Para atendimento desta demanda são necessárias mudas florestais nativas em quantidade e qualidade.

A qualidade das mudas florestais é uma característica intimamente relacionada à correta escolha do tipo de recipiente, substrato e manejo durante a formação (CARNEIRO, 1995). No estado do Rio de Janeiro, o recipiente mais utilizado para produção de mudas florestais são os sacos plásticos e a fonte de matéria orgânica mais comum nos substratos dessas mudas é o esterco bovino (SEA, 2010). No entanto, na região metropolitana do estado, a atividade pecuária é escassa, o que dificulta a disponibilidade de esterco, assim, o biossólido pode ser uma boa alternativa como fonte de matéria orgânica e nutrientes na composição de substrato para a produção de mudas florestais nessa região.

O uso do biossólido como adubo orgânico é uma das alternativas mais promissoras para disposição final deste resíduo, em virtude da viabilidade de uso do material para esse fim e da sustentabilidade de tal destinação (BETTIOL; CAMARGO, 2006). A aplicação do biossólido no substrato pode ser benéfico para produção de mudas florestais, já que o mesmo constitui boa fonte de matéria orgânica e nutrientes, obtendo resultados satisfatórios quando usado como componente orgânico em substratos (TELES et al., 1999; TRIGUEIRO; GUERRINI, 2003).

Entre as espécies utilizadas para restauração florestal do bioma Floresta Atlântica, Peltophorobium dubim (Springer.) Taub. (farinha seca), Lafoensia pacari A. St.-Hil. (dedaleiro) e Ceiba speciosa (A. St.-Hil.) Ravenna (paineira) são bastante recomendadas, já que essas espécies produzem grande quantidade de sementes viáveis anualmente, suas mudas são facilmente obtidas no mercado, são fáceis de trabalhar no viveiro e apresentam rápido crescimento durante a fase de estabelecimento do plantio (CARVALHO, 2003). Como nos projetos de restauração normalmente são plantadas várias espécies são importantes mais estudos sobre a respostas das espécies ao biossólido.

O objetivo desse trabalho foi avaliar diferentes proporções de biossólido como componente de substratos para a produção de mudas em sacos plásticos de três espécies florestais da Floresta Atlântica, avaliando além de aspectos morfológicos, o peso e facilidade de transporte das mudas e o seu desenvolvimento em campo.

\section{MATERIAL E MÉTODOS}

O trabalho foi dividido em duas fases, sendo a primeira com a produção das mudas em viveiro e a segunda em campo, onde se verificou o crescimento inicial das mudas após o plantio.

\section{Fase de viveiro}

O experimento foi conduzido entre agosto e dezembro de 2013 no viveiro do Departamento de Silvicultura, da Universidade Federal Rural do Rio de Janeiro (UFRRJ), localizado no município de Seropédica, RJ. Nesta época a temperatura mínima foi de $17{ }^{\circ} \mathrm{C}$ (alguns dias do mês de agosto) e a máxima entre $36-39{ }^{\circ} \mathrm{C}$ (maioria dos dias da $2^{\mathrm{a}}$ quinzena de novembro e no mês de dezembro).

O biossólido utilizado no experimento foi disponibilizado pela Companhia Estadual de Águas e Esgoto do Rio de Janeiro (CEDAE), sendo proveniente da estação de tratamento de esgoto (ETE) de Alegria, localizada na Zona Norte da cidade do Rio de Janeiro, RJ, bairro do Caju. O esgoto tratado pela ETE Alegria é derivado de áreas urbanas domiciliares e comerciais, não contendo resíduos industriais.

A ETE Alegria realiza tratamento de esgoto a nível secundário, utilizando processos físicos e biológicos, sendo gerado lodo de esgoto nas duas fases do tratamento. O lodo proveniente do processo de tratamento primário é adensado por gravidade, enquanto o do tratamento secundário é adensado por meio de centrífuga. Depois do adensamento, o lodo de ambos os tratamentos foram misturados e levado para digestão anaeróbia, após a qual passa por centrífuga de desaguamento para concentração de sólidos.

O biossólido foi testado conforme preconiza a Resolução CONAMA no 375, de 29 de agosto de 2006 (CONAMA, 2006), sendo analisada a composição química, presença de metais pesados e de potenciais agentes 
patogênicos. O material se encontrava dentro dos parâmetros para uso em atividades agrícolas e florestais, segundo o CONAMA (2006), sendo classificado como tipo A para uso agrícola.

Foram testados três diferentes proporções de biossólido no substrato, substituindo o esterco bovino como fonte de matéria orgânica na composição da mistura. Como testemunha foi utilizado substrato padrão empregado por diversos viveiros florestais do estado do Rio de Janeiro que utilizam sacos plásticos de 9,7 x 20,0 cm (diâmetro x altura) como recipientes (SEA, 2010). O experimento foi composto pelos tratamentos: T1 Testemunha, substrato composto de esterco bovino, solo argiloso e areia na proporção volumétrica de 40-50$10 \%$, respectivamente; T2 - Substrato composto de biossólido, solo argiloso e areia na proporção volumétrica de 20-70-10\%, respectivamente; T3 - Substrato composto de biossólido, solo argiloso e areia na proporção volumétrica de 40-50-10\%, respectivamente; T4 - Substrato composto de biossólido, solo argiloso e areia na proporção volumétrica de $80-10-10 \%$, respectivamente.

A mistura dos componentes dos substratos foi realizada manualmente e após a mesma foram retiradas amostras representativas de cada tratamento, para análise dos teores totais de macronutrientes. O resultado da composição química dos substratos é apresentado na tabela 1.

Tabela 1. Características químicas dos substratos dos diferentes tratamentos avaliados no estudo.

Table 1. Chemical characteristics of the substrate of the different treatments evaluated in the study.

\begin{tabular}{|c|c|c|c|c|c|c|c|c|c|c|}
\hline \multirow{2}{*}{ Substrato $(\% \mathrm{v} / \mathrm{v})$} & \multirow{2}{*}{$\begin{array}{c}{ }^{* 1} \mathbf{p H} \\
\left(\mathrm{H}_{2} \mathrm{O}\right)\end{array}$} & ${ }^{* 2} \mathbf{P}$ & ${ }^{* 2} \mathbf{K}^{+}$ & ${ }^{* 3} \mathrm{Ca}^{2+}$ & ${ }^{* 3} \mathrm{Mg}$ & ${ }^{* 3} \mathrm{Al}^{3+}$ & CTC(t & $\mathbf{V}$ & ${ }^{* 4}$ MO & ${ }^{5} \mathbf{N}$ \\
\hline & & \multicolumn{3}{|c|}{------'mg dm'------- } & \multicolumn{2}{|c|}{$-\mathrm{cmol}_{\mathrm{c}} \mathrm{dm}^{-3}--$} & \multicolumn{2}{|c|}{-----\% \%---. } & \multicolumn{2}{|c|}{$--\mathrm{g} \mathrm{kg}^{-1}--$} \\
\hline $40: 50: 10^{*}$ & 6,9 & 103,3 & 527 & 1,65 & 2,00 & 0,0 & 5,00 & 78,1 & 48,0 & 1,75 \\
\hline $20: 70: 10 * *$ & 5,0 & 163,3 & 41 & 3,29 & 1,34 & 0,1 & 4,84 & 63,7 & 23,0 & 1,78 \\
\hline $40: 50: 10 * *$ & 5,3 & 223,7 & 52 & 7,08 & 2,17 & 0,0 & 9,38 & 72,8 & 60,8 & 2,13 \\
\hline $80: 10: 10 * *$ & 5,4 & 567,9 & 87 & 10,67 & 3,46 & 0,1 & 14,45 & 97,0 & 198,3 & 2,18 \\
\hline
\end{tabular}

${ }^{11} \mathrm{pH}$ em água, $\mathrm{KCl}$ e $\mathrm{CaCl}_{2}$ - Relação 1:2,5; ${ }^{2}$ Extrator Mehlich 1; ${ }^{3}$ Extrator: $\mathrm{KCl}$ - $1 \mathrm{~mol} / \mathrm{L} ; \mathrm{CTC}(\mathrm{t})$ - Capacidade de Troca Catiônica Efetiva; V - Índice de Saturação de Bases; ${ }^{* 4} \mathrm{C}$. Org x 1,724 - Walkley-Black; ${ }^{* 5} \mathrm{~N}$ total - Digestão Sulfúrica - Destilação Kjeldhal.

*Proporções volumétricas, em sequência, de esterco bovino, solo argiloso e areia;

**Proporções volumétricas, em sequência de biossólido; solo argiloso e areia.

As espécies utilizadas no experimento foram Peltophorobium dubim (Springer.) Taub. (Farinha seca), Lafoensia pacari A. St.-Hil. (Dedaleiro) e Ceiba speciosa (A. St.-Hil.) Ravenna (Paineira). Estas três espécies florestais são nativas da Floresta Atlântica, de rápido crescimento e comumente encontradas em plantios para restauração florestal. As sementes utilizadas foram coletadas em fragmentos florestais da região As sementes utilizadas foram coletadas em fragmentos florestais na Baixada Fluminense, região do estado do Rio de Janeiro na qual está inserido o município de Seropédica. A coleta das sementes foi realizada em 10 ou mais árvores de cada espécie, sempre que possível em indivíduos dentro de fragmentos florestais, sendo em alguns casos realizada coleta em indivíduos isolados. Foi realizada a semeadura direta, sendo utilizadas de 3 a 5 sementes por recipiente. Após a germinação foi realizado um desbaste, deixando uma plântula por recipiente, de preferência a mais central e ou mais vigorosa.

O delineamento experimental utilizado foi o inteiramente casualizado (DIC), com quatro tratamentos em quatro repetições. Cada repetição foi composta por 12 mudas, o que resultou em 48 mudas por tratamento, 192 por espécie e 576 mudas no total. Para cada uma das espécies foi montado um experimento independente, com os mesmos tratamentos e delineamento.

A produção das mudas seguiu padrão comum em viveiros de sacos plásticos, com irrigação, limpeza e rustificação. As mudas foram produzidas tendo como recipientes sacolas plásticas nas dimensões de 9,7 x $20 \mathrm{~cm}$ (diâmetro $\mathrm{x}$ altura). A semeadura direta foi realizada com os recipientes em casa de vegetação, após a germinação e o desbaste, as mudas foram levadas para canteiros a pleno sol. A irrigação das mudas foi realizada por microaspersão, sendo o sistema ligado duas vezes por dia, a primeira no início da manhã e a segunda no final da tarde. Durante o acompanhamento das mudas, sempre que verificada a necessidade, foi realizada monda, retirando manualmente as plantas daninhas presentes em cada recipiente. Não foram realizadas adubações, tendo em vista que todos os substratos levaram componentes ricos em matéria orgânica e nutrientes (esterco e biossólido). A rustificação das mudas foi realizada na semana anterior à expedição e consistiu em redução da irrigação, nesse período as mudas foram irrigadas apenas uma vez por dia, pela manhã.

As avaliações consistiram na mensuração da altura da parte aérea ao longo do tempo de formação das mudas, com uso de régua graduada. Devido às diferentes características das espécies, às condições locais e a necessidade de levar as mudas para plantio nos meses de novembro e ou dezembro (época de maior precipitação e portanto, mais indicada para o plantio), os períodos de avaliações diferiram entre as espécies. Para farinha seca e dedaleiro as medições de altura ocorreram a cada 21 dias sendo realizadas aos 47, 68, 89 e 110 dias após a semeadura. As mudas de paineira, por apresentarem maior crescimento inicial, tiveram seu período de

FLORESTA, Curitiba, PR, v. 47, n. 2, p. 165 - 176, abr. / jun. 2017.

Cabreira, G. V. et al.

ISSN eletrônico 1982-4688

DOI: $10.5380 /$ rf.v47i1.44291 
mensuração reduzido para intervalos de 15 dias, sendo realizadas aos 39, 60, 75 e 90 dias após a semeadura. Para todas as espécies, na última medição, além da altura mediu-se também o Diâmetro do Coleto (DC), com paquímetro digital.

Após a última medição foram selecionadas quatro mudas de cada repetição (resultando em 16 por tratamento), com altura e diâmetro mais próximos da média. Estas mudas foram levadas para o laboratório e irrigadas com 0,5 litro de água, com objetivo de padronizar seu teor de umidade. Após 24 horas, as mudas foram pesadas individualmente, com objetivo de obter o peso médio da muda no momento da expedição para o campo.

As mesmas mudas utilizadas para avaliação do peso médio na expedição (4 por repetição e 16 por tratamento, para cada espécie) foram depois destruídas e fracionadas para a determinação dos seguintes parâmetros: área foliar, por meio de medidor LICOR 3600; biomassa da parte aérea e biomassa de raízes. Cada parte da muda foi devidamente identificada e acondicionada em sacos de papel para secagem em estufa de circulação de ar forçada a temperatura de $65^{\circ} \mathrm{C}$, por 72 horas. Após isso, o material foi pesado para obtenção da matéria seca de parte aérea (MSPA) e matéria seca de raízes (MSR). Assim obteve a matéria seca total (MST). Com os dados desses parâmetros foi também determinado o índice de qualidade de Dickson (IQD).

O índice de qualidade de Dickson (IQD) foi determinado por meio da matéria seca total (MST), em função da altura da parte aérea $(\mathrm{H})$, do diâmetro do coleto (DC), do peso de matéria seca da parte aérea (MSPA) e do peso de matéria seca das raízes (MSR), através da fórmula:

\section{$\frac{M S T(g)}{H(\mathrm{~cm}) / D C(\mathrm{~mm})+\operatorname{MSPA}(\mathrm{g}) / \operatorname{MSR}(\mathrm{g})}$}

Após a tabulação dos dados, foram elaborados gráficos com as médias de crescimento de altura em função do tempo para cada espécie. Os dados de altura (na última avaliação), diâmetro do coleto, área foliar, MSPA, MSR, MST e IQD foram submetidos à análise de variância $(\mathrm{P} \geq 0,95)$ e, quando constatadas diferenças significativas, ao teste de Tukey $(\mathrm{P} \geq 0,95)$. Para as análises estatísticas foi utilizado o software Sistema de Análise Estatística e Genética (SAEG, 2007).

\section{Fase de campo}

Considerando que para cada uma das espécies avaliadas haviam quatro repetições de 12 mudas por tratamento, sendo, portanto, o número total de 48 mudas por tratamento, e que 16 mudas de cada tratamento (quatro de cada repetição) já haviam sido destruídas para aferir biomassa e outros parâmetros, um total de 32 mudas (oito de cada repetição) restaram para o experimento em campo. A fim de avaliar a taxa de sobrevivência e o crescimento inicial em campo foram selecionadas, entre as 32 mudas restantes de cada espécie, as 20 que apresentavam altura mais próxima da média de cada tratamento, as quais foram plantadas em campo. As 12 mudas restantes em cada tratamento também foram plantadas em campo, mas sem compor um experimento, não sendo avaliadas.

O plantio foi realizado em área de reflorestamento da Pequena Central Hidrelétrica (PCH) Santa Rosa, no município de Bom Jardim, RJ. A área apresenta altitude média de 530 metros e relevo de ondulado a montanhoso, sendo o solo predominante na região de textura argilo-arenosa, caracterizado como LATOSSOLO VERMELHO AMARELO Distrófico, podendo ser considerado como de baixa fertilidade natural.

Com base em dados climáticos da Rede do INMET, da estação meteorológica de Cordeiro, RJ (a mais próxima da área do experimento) foi construído gráfico da precipitação total e média da temperatura máxima semanal (Figura 1), a fim de subsidiar informações das taxas de sobrevivência e crescimento inicial no campo. $\mathrm{O}$ clima da região é caracterizado, segundo Koppen como Aw, ou seja, tropical chuvoso com inverno seco e verão com chuvas. 


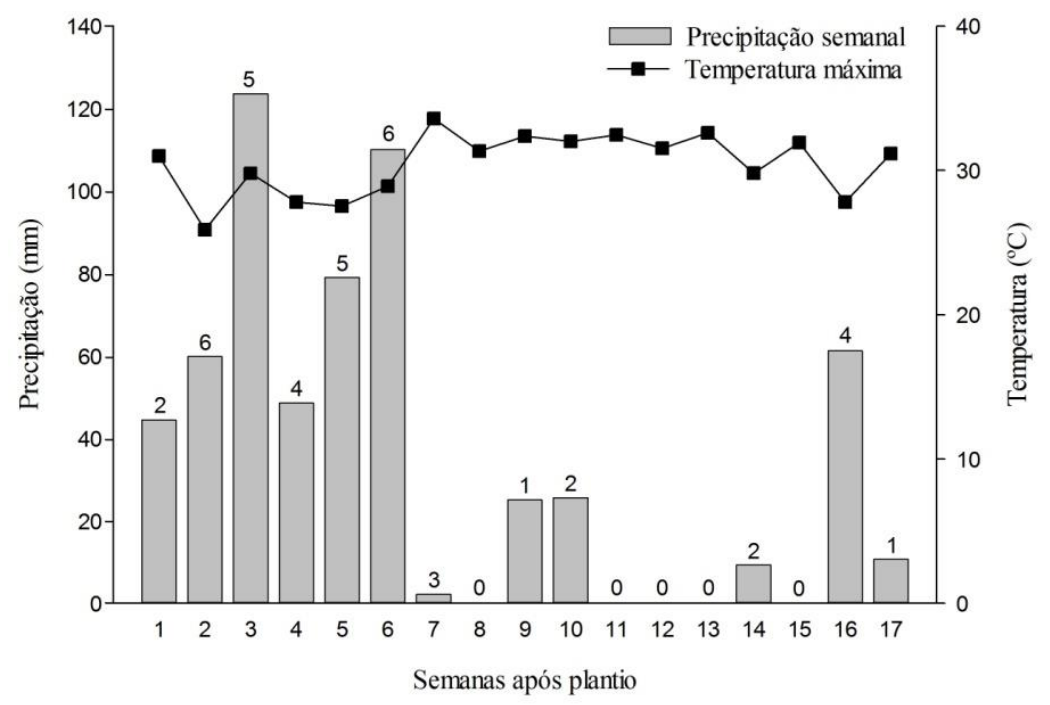

Figura 1. Precipitação total e média da temperatura máxima semanal da região de Bom Jardim, RJ, a partir da data de plantio da paineira em 20 de novembro de 2013. Os números sobre a barra referem-se a quantidade de dias com precipitação daquela semana.

Figure 1. Total precipitation and weekly average of maximum temperature of Bom Jardim, RJ, from the date of planting the ceiba, in 20 November 2013. Numbers above the bars indicate the amount of days with precipitation in that week.

A vegetação predominante na área era de capim braquiária (Urochloa brizantha (A. Rich) Stapf vr.). O preparo da área consistiu em roçada da braquiária, 30 dias após aplicação de glyphosate na dose de 3 litros por hectare. Vinte dias após, marcação e abertura das covas, nas dimensões de $30 \times 30 \times 30 \mathrm{~cm}$, adotando o espaçamento 2,0 x 1,5 m. Tal espaçamento foi adotado para reduzir os custos do experimento com manutenção, devido a gramínea agressiva presente na área, bem como para o melhor aproveitamento da área disponível para o plantio. A adubação de plantio foi de $100 \mathrm{~g}$ de NPK 06-30-06 por cova. O plantio das mudas de paineira foi realizado no dia 19 de novembro/2013 e o de dedaleiro e farinha seca no dia 19 de dezembro/2013.

O delineamento experimental foi inteiramente casualisado (DIC), com 20 repetições de uma planta para cada tratamento. $\mathrm{O}$ experimento foi implantado junto com o reflorestamento da empresa, a fim de evitar naquela área a presença apenas das 3 espécies deste estudo. Imediatamente após o plantio, nas mudas de cada tratamento foi amarrada uma fita de cor diferente (vermelho, azul, amarelo e preta), para posteriormente identificar no delineamento de qual tratamento era proveniente cada muda. Também foi preparado um croqui com a localização de cada muda. Assim foram plantadas 20 mudas por tratamento, resultando em 80 mudas por espécies, que totalizaram 240 mudas na área experimental.

Os tratos culturais foram controle das formigas cortadeiras através de rondas e, quando necessário, colocação de iscas formicidas. Aos 2 e 5 meses após o plantio foram realizados coroamento e roçada. Aos 5 meses após o plantio avaliou-se a sobrevivência das plantas e mediu-se a altura e o diâmetro ao nível do solo (DNS) com vara graduada $(\mathrm{cm})$ e paquímetro $(\mathrm{mm})$, respectivamente.

\section{RESULTADOS E DISCUSSÃO}

\section{Fase de viveiro}

Para as três espécies, de modo geral, a partir da $2^{\mathrm{a}}$ medição existe tendência de maior crescimento em altura das mudas nos substratos com maiores proporções volumétricas de biossólido, o que é confirmado pelas diferenças significativas da última medição (época de expedição das mudas para o campo) e menor crescimento médio significativo das mudas produzidas no substrato com esterco bovino (Figura 2).

Considerando para o recipiente utilizado a altura da parte aérea de $30 \mathrm{~cm}$ como adequada para expedição (SCREMIN-DIAS et al., 2006), observa-se que os tratamentos com maiores proporções de biossólido apresentaram menor tempo para formação das mudas. Tal característica, em geral, é positiva para os viveiristas, tendo em vista que quando atrelada à adequada rustificacão, tende a diminuir os custos de produção e maximizar o uso do espaço no viveiro, permitindo inclusive mais ciclos de produção de mudas.

FLORESTA, Curitiba, PR, v. 47, n. 2, p. 165 - 176, abr. / jun. 2017.

Cabreira, G. V. et al.

ISSN eletrônico 1982-4688

DOI: $10.5380 /$ rf.v47i1.44291 
É possível inferir que, usando $40 \%$ de biossólido no substrato, forma-se mudas de farinha seca, dedaleiro e paineira com aproximadamente 80, 80 e 60 dias após a semeadura, respectivamente. Usando $40 \%$ de esterco, este valor mínimo de altura de $30 \mathrm{~cm}$, não foi atingido até a última medição (110 e 90 dias após a semeadura) das mudas de farinha seca e paineira e para dedaleiro só foi atingido aos 100 dias após a semeadura. No substrato com $80 \%$ de biossólido, esta altura foi atingida com aproximadamente 75, 80 e 60 dias após a semeadura, evidenciando o potencial de redução do tempo das mudas com uso de biossólido. A eficiência do biossólido como ferramenta possível para o encurtamento do ciclo de produção também foi observada por Basil et al. (2009) para mudas de Austrocedrus chilensis, por Varela e Martinez (2013) para Nothofagus alpina.
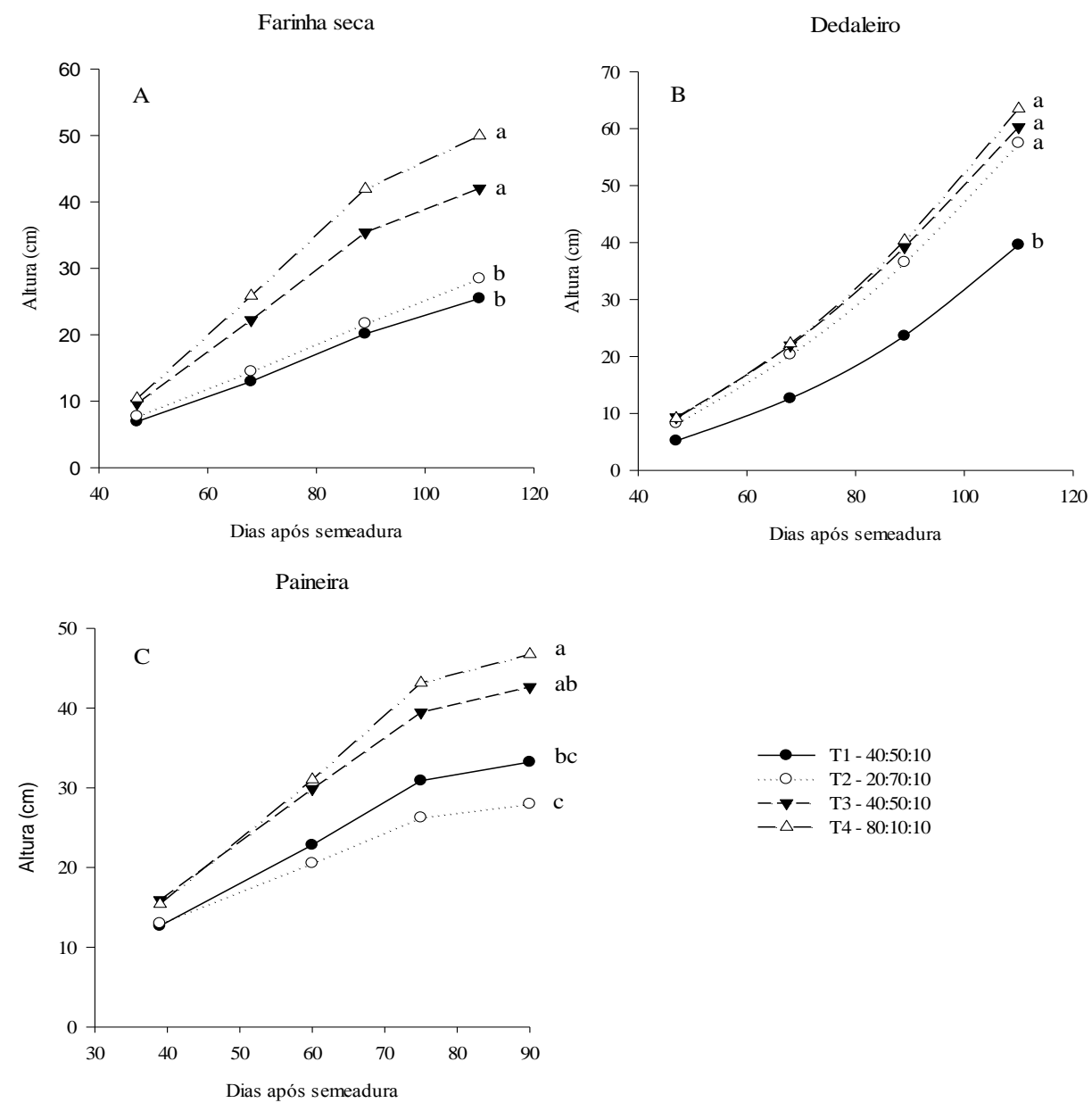

Figura 2. Crescimento médio em altura de mudas de Peltophorobium dubim (A), Lafoensia pacari (B) e Ceiba speciosa $(\mathrm{C})$ em diferentes épocas, produzidas com substrato utilizando proporções volumétricas de esterco bovino, solo argiloso e areia - 40:50:10 (T1) e três substratos com diferentes proporções de biossólido e solo argiloso - 20:70; 40:50 e 80:10, com 10\% de areia, respectivamente T2, T3 e T4. Médias seguidas pela mesma letra, na última medição, não diferem estatisticamente pelo teste de Tukey $(\mathrm{P} \geq 0,95)$.

Figure 2. Average growth in height of the seedlings of Peltophorum dubium (Figure 1A), Lafoensia pacari (Figure 1B) e Ceiba speciosa (Figure 1C) in different times, produced in a substrate with different proportions of cattle manure, clay and sand 40:50:10 (T1) and three substrate with differents proportions of biosolid, clay and sand 20:70; 40:50 e 80:10, respectively T2, T3 and T4. Average values followed by the same letter, in the last measurement, do not statistically differ by the Tukey test $(\mathrm{P} \geq 0,95)$.

Os dados da última medição (Figura 2), em conjunto com os da tabela 2, verifica-se que, de modo geral, na época de expedição para campo, as mudas produzidas no substrato com $80 \%$ de biossólido apresentaram crescimento significativamente superior ao observado nos demais substratos. Na situação inversa, as mudas produzidas com esterco, em geral, apresentaram valores médios significativamente inferiores. Isto ocorre 
provavelmente devido aos maiores teores de matéria orgânica e nutrientes (exceto potássio) no substrato formado por $80 \%$ de biossólido e os menores teores do substrato com esterco (Tabela 1). Faustino et al. (2005), relatam que os acréscimos de matéria orgânica no substrato estão relacionados aos incrementos em altura das espécies produzidas. Diferentes estudos têm mostrado que substratos ricos em matéria orgânica propiciam melhor crescimento das mudas com boa formação do sistema radicular e melhor balanço nutricional (CALDEIRA et al., 2007), tal qual observado nos resultados do presente trabalho.

A resposta positiva das espécies florestais nativas à aplicação de matéria orgânica no substrato provavelmente ocorre, entre outros fatores, devido ao fato de os solos florestais apresentarem elevado teor de matéria orgânica, decorrente da decomposição de serapilheira, não existentes em solos degradados e ou cultivados. Outro fator que pode ter contribuído no maior crescimento das mudas em substratos com doses crescentes de biossólido foi o teor de fósforo, que variou de 103 a $568 \mathrm{mg} / \mathrm{dm}^{3}$ entre os substratos com esterco e $80 \%$ de biossólido. O fósforo é um nutriente importante para o arranque inicial das mudas após a emergência da plântula, conforme mencionam Gonçalves e Poggiani (2000), sendo assim a maior presença desse nutriente no substrato pode ter favorecido o crescimento das mudas nos tratamentos com maiores proporções de biossólido.

Tabela 2. Valores médios de variáveis de crescimento de mudas das três espécies florestais produzidas em diferentes substratos, na época de expedição para o campo.

Table 2. Mean values of growth variables of seedlings from the three forest species produced in different substrate, by the time they were taken to planting.

\begin{tabular}{|c|c|c|c|c|c|}
\hline \multirow{2}{*}{ Espécie } & \multirow{2}{*}{ Parâmetro } & \multicolumn{4}{|l|}{ Tratamento } \\
\hline & & 40:50:10* & $20: 70: 10^{* *}$ & $40: 50: 10 * *$ & $80: 10: 10 * *$ \\
\hline \multirow{5}{*}{$\begin{array}{l}\text { Peltophorobium dubim } \\
\text { (Farinha seca) }\end{array}$} & Diâmetro (mm) & $4,6 \mathrm{c}$ & $4,8 \mathrm{c}$ & $6,3 \mathrm{~b}$ & $7,7 \mathrm{a}$ \\
\hline & Massa seca raiz (g) & $3,64 \mathrm{~b}$ & $3,42 \mathrm{~b}$ & $4,03 \mathrm{~b}$ & $5,18 \mathrm{a}$ \\
\hline & Massa seca aéreo (g) & $6,31 \mathrm{c}$ & $6,92 \mathrm{~b}$ & $11,27 \mathrm{a}$ & $18,85 \mathrm{a}$ \\
\hline & Área foliar $\left(\mathrm{cm}^{2}\right)$ & $206,6 \mathrm{c}$ & $287,3 \mathrm{bc}$ & $434,8 \mathrm{~b}$ & $917,6 \mathrm{a}$ \\
\hline & IQD & $1,37 \mathrm{~b}$ & $1,31 \mathrm{~b}$ & $1,63 \mathrm{~b}$ & $2,37 \mathrm{a}$ \\
\hline \multirow{5}{*}{$\begin{array}{l}\text { Lafoensia pacari } \\
\text { (Dedaleiro) }\end{array}$} & Diâmetro (mm) & $3,6 \mathrm{~b}$ & $4,8 \mathrm{a}$ & $4,9 \mathrm{a}$ & $5,4 \mathrm{a}$ \\
\hline & Massa seca Raiz (g) & $2,88 \mathrm{~b}$ & $3,17 \mathrm{a}$ & $3,21 \mathrm{a}$ & $3,21 \mathrm{a}$ \\
\hline & Massa seca Aéreo (g) & $4,52 \mathrm{~b}$ & $8,05 \mathrm{a}$ & $8,00 \mathrm{a}$ & $9,04 \mathrm{a}$ \\
\hline & Área foliar $\left(\mathrm{cm}^{2}\right)$ & $178,7 \mathrm{~b}$ & $457,3 \mathrm{a}$ & $473,9 \mathrm{a}$ & $577,3 \mathrm{a}$ \\
\hline & IQD & $0,60 \mathrm{~b}$ & $0,77 \mathrm{ab}$ & $0,76 \mathrm{ab}$ & $0,84 \mathrm{a}$ \\
\hline \multirow{5}{*}{$\begin{array}{l}\text { Ceiba speciosa } \\
\text { (Paineira) }\end{array}$} & Diâmetro (mm) & $6,7 \mathrm{~b}$ & $6,2 \mathrm{~b}$ & $7,4 \mathrm{ab}$ & $8,4 \mathrm{a}$ \\
\hline & Massa seca raiz (g) & $3,72 \mathrm{~b}$ & $3,20 \mathrm{~b}$ & $3,64 \mathrm{~b}$ & $4,76 \mathrm{a}$ \\
\hline & Massa seca aéreo $(\mathrm{g})$ & $5,54 \mathrm{~b}$ & $5,04 \mathrm{~b}$ & $7,51 \mathrm{a}$ & $8,84 \mathrm{a}$ \\
\hline & Área foliar $\left(\mathrm{cm}^{2}\right)$ & $177,7 \mathrm{c}$ & $147,5 \mathrm{c}$ & $366,5 \mathrm{~b}$ & $483,5 \mathrm{a}$ \\
\hline & IQD & $1,47 \mathrm{a}$ & $1,35 \mathrm{a}$ & $1,43 \mathrm{a}$ & $1,84 \mathrm{a}$ \\
\hline
\end{tabular}

Médias seguidas pela mesma letra na linha não diferem estatisticamente pelo teste de Tukey $(\mathrm{P} \geq 0,95)$.

*Proporções volumétricas, em sequência, de esterco bovino, solo argiloso e areia;

**Proporções volumétricas, em sequência de biossólido; solo argiloso e areia.

Em relação ao diâmetro, os resultados em crescimento médio foram semelhantes aos observados para altura nas três espécies (Tabela 2). Em que, o tratamento com $80 \%$ de biossólido apresentou melhores resultados, o que provavelmente ocorreu em função dos elevados teores de $\mathrm{N}$ e $\mathrm{P}$ contidos neste tratamento. Estes nutrientes são altamente requeridos nos estádios iniciais de crescimento das mudas, com papel importante no arranque inicial do crescimento da parte aérea, o que justifica as maiores médias em altura e diâmetro nos tratamentos com maiores teores destes nutrientes (FARIA et al., 2013; TRAZZI et al., 2014; ABREU et al., 2017). Segundo Carneiro (1995) existe uma tendência de maior crescimento em diâmetro nas plantas com maior crescimento em altura, devido a mecanismos que as plantas dispõem para ajustar o crescimento do diâmetro do coleto com o do restante da parte aérea. Este equilíbrio de crescimento evita que as plantas apresentem estiolamento, sendo que o tombamento decorrente desta característica pode resultar em morte ou deformações das plantas no campo (ABREU et al., 2015).

De modo geral, as mudas produzidas nos substratos com $80 \%$ de biossólido apresentaram valores significativamente superior de diâmetro de colo e peso de matéria seca de raízes, parâmetros considerados importantes como indicadores do potencial de resistência das mudas às condições de campo (CARNEIRO, 1995), principalmente quando ocorrem estiagens após o plantio. A massa seca de raízes é reconhecida como uma das melhores características morfológicas para estimar a sobrevivência e crescimento inicial das mudas no campo (CRUZ et al., 2006), pois, de acordo com José et al. (2009) e Caldeira et al. (2012), o sistema radicular

FLORESTA, Curitiba, PR, v. 47, n. 2, p. 165 - 176, abr. / jun. 2017.

Cabreira, G. V. et al.

ISSN eletrônico 1982-4688

DOI: $10.5380 /$ rf.v47i1.44291 
deve apresentar tamanho suficiente para garantir o suprimento de água e nutrientes para a parte área das plantas após o plantio.

Quando analisada a massa seca de raiz e parte aérea observa-se um aumento progressivo da biomassa das plantas a partir do acréscimo na proporção do biossólido, ou seja, o aumento das doses de biossólido no substrato proporcionou melhor aproveitamento dos nutrientes pela planta e consequente aumento na produção de MSR e MSPA. Abreu et al. (2017) ao testar diferentes resíduos sólidos urbanos para produção de mudas de Lafoensia pacari, atribuíram o acréscimo de biomassa nos tratamentos com biossólido aos altos teores de $\mathrm{P}$ contidos neste resíduo. A maior biomassa de raízes no tratamento T4 pode ser considerada uma característica desejável, tendo em vista que, o melhor crescimento da raiz é importante para dar suporte à massa de matéria verde produzida pelas plantas, sendo esse crescimento em consequência das propriedades químicas e físicas dos substratos (CARNEIRO, 1995).

Para as médias de área foliar, o tratamento T4 apresentou maiores valores que os demais tratamentos, para todas as espécies. Esta é uma variável de grande importância na avaliação da qualidade de mudas, pois a quantidade de fotoassimilados na planta é, geralmente, proporcional à sua área foliar (CAVALCANTE et al., 2016). Carneiro (1995) destaca ainda que mudas florestais com maior área foliar, após o plantio, tem condições de produzir mais fotoassimilados e com isso apresentar maior crescimento do sistema radicular e melhores taxas de sobrevivência e crescimento inicial no campo.

Ao comparar o crescimento médio das mudas dos tratamentos com $40 \%$ de esterco e com $40 \%$ de biossólido na época de expedição para o campo (Figura 2 e Tabela 2), constata-se que as produzidas com biossólido apresentaram crescimento significativamente superior. Isto ocorreu provavelmente devido ao maior teor de nutrientes, exceto potássio (Tabela 1), bem como a maior capacidade de troca catiônica (CTC) e matéria orgânica, dos substratos com biossólido.

O menor teor de potássio dos substratos com biossólido se explica pelo fato desse nutriente ser muito solúvel e permanecer dissolvido na água durante o processo de tratamento de esgoto, não precipitando para o lodo (BERTON; NOGUEIRA, 2010). No presente trabalho, o menor teor de potássio presente no biossólido parece não ter sido limitante para o crescimento das mudas das três espécies estudadas. Isto ocorreu provavelmente devido a boa capacidade de retenção de nutrientes em substratos com argila e matéria orgânica, como os utilizados na produção de mudas em sacos plásticos.

Além disso, o pH do substrato quando se utilizou o esterco era de 6,9 e com biossólido variou de 5,0 a 5,3, segundo Malavolta (1989), valores de pH no intervalo entre 5,5 a 6,5 são mais indicados para uma melhor absorção de maioria dos macronutrientes e micronutrientes. No presente trabalho, é provável que o $\mathrm{pH}$ do substrato com esterco tenha desfavorecido a absorção de nutrientes, levando ao menor crescimento das mudas, quando comparado com as produzidas com biossólido.

Os resultados evidenciam o potencial não só do uso do biossólido para produção de mudas florestais, como da possibilidade de o mesmo substituir o esterco bovino na produção de mudas em sacos plásticos, principalmente em locais onde não existem criação intensiva de gado, como nas áreas urbanas do estado Rio de Janeiro. Além da utilização do biossólido para produção de mudas, consistir em melhor alternativa de destino final desse material em relação a atual disposição em aterros sanitários.

Avaliando a produção de mudas de Lafoensia pacari em tubetes de $110 \mathrm{~cm} 3$, utilizando como substratos composto de casca de Pinus e vermiculita; e resíduos de podas de árvores compostadas com lodo de esgoto, nas proporções de 3:1 (v:v) e 2:1 (v:v), Scheer et al. (2012) verificaram melhores resultados para as mudas verificaram melhores resultados para as mudas produzidas a partir da utilização de lodo de esgoto compostado, sendo a proporção 2:1 considerada a melhor para a produção dessa espécie. Resultado semelhante ao do presente trabalho, onde o dedaleiro apresentou maior crescimento e biomassa no substrato com a maior dose de biossólido.

Os estudos de Trigueiro e Guerrini (2003), com mudas de Eucalyptus grandis, e Caldeira et al. (2012), com a espécie Toona ciliata, ambas pioneiras de rápido crescimento, como as testadas no presente trabalho, também observaram maior crescimento das mudas em substratos com maiores proporções de biossólido.Tal resultado evidencia o potencial deste material também para produção de mudas de espécies exóticas utilizadas na silvicultura econômica, visando principalmente a produção de madeira.

Quanto ao índice de qualidade de Dickson (IQD) constatou-se que, em média, as mudas do tratamento com $80 \%$ de biossólido apresentaram maiores valores. Fonseca et al. (2002), destaca que o índice de qualidade de Dickson é um importante indicador da qualidade das mudas, pois no seu cálculo são considerados a robustez e o equilíbrio da distribuição da biomassa na muda, ponderando os resultados de vários parâmetros importantes, empregados para avaliação da qualidade. Para Gomes et al. (2003), quanto maior IQD, maior qualidade terá a muda avaliada. Dessa forma, um maior valor desse índice pode sugerir maior qualidade e capacidade das mudas de sobreviverem no campo, contudo, isso pode variar de espécie para espécie.

As médias de IQD variaram de 1,37 a 2,37 para a farinha seca e 0,60 a 0,84, para o dedaleiro, sendo que para a farinha seca o T4 se sobressaiu sobre os demais, já para o dedaleiro, os tratamentos com a presença do 
biossólido se mostraram semelhantes estatisticamente. Para a paineira os resultados foram diferentes dos de outras espécies, observou-se que todos os tratamentos foram semelhantes estatisticamente, variando o IQD entre 1,35 e 1,84, demonstrando que para essa espécie os tratamentos geraram mudas de qualidade semelhante.

O IQD é um parâmetro interessante, que leva em consideração as variáveis mais importantes para avaliar a qualidade de mudas, sendo sua aplicação calibrada para as mudas de espécies exóticas de interesse na silvicultura (ROSSA et al., 2013). No entanto para espécies nativas são necessárias mais pesquisas para que o IQD possa ser utilizado de forma confiável, tem-se observado que para cada espécie ou grupo de espécies os valores de IQD para indicar qualidade das mudas seriam diferentes uns dos outros (CALDEIRA et al., 2014). Portanto, tal índice deve ser avaliado com extrema atenção.

Um fator importante e pouco avaliado, quando se estuda componentes de substrato para produção de mudas em sacos plásticos, é peso das mudas com os recipientes no momento de sua expedição para campo. Os valores médios das mudas nos recipientes foram $1,25 \mathrm{~kg}$ no substrato do $\mathrm{T} 1 \mathrm{e}$ de 1,33; 0,98 e $0,91 \mathrm{~kg}$, respectivamente nos substratos dos tratamentos T2, T3 e T4. Estas diferenças de peso ocorrem devido as densidades dos materiais utilizados: solo argiloso > esterco bovino > biossólido. O menor peso do substrato e, em consequência, das mudas, pode ser uma vantagem para a atividade de restauração florestal, pois facilita o transporte das mudas do viveiro para o local de plantio. Como exemplo prático, para um caminhão carregado com 6.000 mudas produzidas com esterco no substrato, o peso das mudas seria em torno de 7,5 toneladas. Levando a mesma quantidade de mudas com um substrato composto por $80 \%$ de biossólido o peso seria de 5,5 toneladas, resultando em economia de combustível, maior facilidade de carregar e descarregar o caminhão e, dependendo da capacidade limite de peso do veículo, a possibilidade de transportar maior número de mudas por viagem.

O menor peso das mudas facilita também o deslocamento das mesmas em campo, do viveiro temporário ou local de armazenamento, até as covas de plantio. Normalmente esse transporte é feito com caixas plásticas que, considerando as dimensões dos sacos plásticos utilizados, comportam em torno de 20 mudas. Dessa forma, as 20 mudas do tratamento com $80 \%$ de biossólido apresentariam peso de $18,2 \mathrm{~kg}$ e o tratamento com esterco em torno de $25,0 \mathrm{~kg}$. Comparando o uso de $40 \%$ de biossólido com $40 \%$ de esterco essa diferença por caixa de muda transportada é de aproximadamente $5 \mathrm{~kg}$. O menor peso das mudas nesse caso diminui o esforço dos trabalhadores de campo, além de ser ergonomicamente mais adequada, podendo obter maior rendimento na operação de plantio, levando a redução dos custos para a formação do povoamento visando a restauração florestal.

\section{Fase de campo}

Aos cinco meses após o plantio, as plantas das três espécies apresentaram taxa de sobrevivência em campo superior a 90\% para todos os tratamentos avaliados (Tabela3). Segundo Belloto et al. (2009) para plantios de restauração florestal haverá necessidade da operação de replantio, caso a taxa de sobrevivência das mudas em campo seja menor do que $90 \%$. Para o estado do Rio de Janeiro, segundo Art. $8^{\circ}$, item 4.2, da Resolução INEA $n^{\circ} 89$, de 03/06/14 (INEA, 2014), é aceitável índice de mortalidade por espécie de até 20\%. Os valores encontrados para as três espécies nesse trabalho se enquadram em ambas as recomendações.

Tabela 3. Sobrevivência e crescimento inicial de mudas de três espécies florestais produzidas em diferentes substratos, cinco meses após o plantio, em área de reflorestamento da PCH Santa Rosa, município de Bom Jardim, RJ.

Table 3. Survival and initial growth of seedlings of three forest species produced in different substrate, five month after planting, in reforestation area of PCH Santa Rosa in the city of Bom Jardim, RJ.

\begin{tabular}{|c|c|c|c|c|}
\hline Espécie & Substrato & Sobrev. (\%) & Altura $(\mathrm{cm})$ & DNS (mm) \\
\hline \multirow{4}{*}{$\begin{array}{l}\text { Lafoensia paccari } \\
\text { (Dedaleiro) }\end{array}$} & $80: 10: 10 \% *$ & 100 & $105 \mathrm{a}$ & $14,8 \mathrm{a}$ \\
\hline & $40: 50: 10 \% *$ & 100 & $94 \mathrm{ab}$ & $12,4 \mathrm{a}$ \\
\hline & $20: 70: 10 \% *$ & 100 & $86 \mathrm{~b}$ & $12,3 \mathrm{a}$ \\
\hline & $40: 50: 10 \% * *$ & 95 & $87 \mathrm{~b}$ & $12,9 \mathrm{a}$ \\
\hline \multirow{4}{*}{$\begin{array}{l}\text { Peltophorobium dubim } \\
\text { (Farinha seca) }\end{array}$} & $80: 10: 10 \% *$ & 100 & $96 \mathrm{a}$ & $22,3 \mathrm{a}$ \\
\hline & $40: 50: 10 \% *$ & 95 & $84 \mathrm{ab}$ & $20,5 \mathrm{ab}$ \\
\hline & $20: 70: 10 \% *$ & 95 & $73 \mathrm{~b}$ & $18,1 \mathrm{~b}$ \\
\hline & $40: 50: 10 \% * *$ & 95 & $78 \mathrm{~b}$ & $19,4 \mathrm{ab}$ \\
\hline \multirow{4}{*}{$\begin{array}{l}\text { Ceiba speciosa } \\
\text { (Paineira) }\end{array}$} & $80: 10: 10 \% *$ & 100 & $87 \mathrm{a}$ & $29,3 \mathrm{a}$ \\
\hline & $40: 50: 10 \% *$ & 100 & $78 \mathrm{a}$ & $26,4 \mathrm{a}$ \\
\hline & $20: 70: 10 \% *$ & 100 & $68 \mathrm{a}$ & $22,0 \mathrm{a}$ \\
\hline & $40: 50: 10 \% * *$ & 95 & $79 a$ & $25,1 \mathrm{a}$ \\
\hline
\end{tabular}

Para a mesma espécie, médias seguidas pela mesma letra, na coluna, não diferem estatisticamente pelo teste de Tukey (P $\geq 0,95)$.

*Proporções volumétricas, em sequência de biossólido; solo argiloso e areia.

**Proporções volumétricas, em sequência, de esterco bovino, solo argiloso e areia.

FLORESTA, Curitiba, PR, v. 47, n. 2, p. 165 - 176, abr. / jun. 2017.

Cabreira, G. V. et al.

ISSN eletrônico 1982-4688

DOI: $10.5380 /$ rf.v47i1.44291 
A sobrevivência e o crescimento inicial das plantas florestais estão diretamente relacionados com a qualidade das mudas utilizadas no plantio. Parâmetros morfológicos, como altura e diâmetro do coleto, podem ser bons indicativos de qualidade e consequentemente, sobrevivência dessas plantas em campo (Fonseca et al., 2002). Os elevados índices de sobrevivência verificados podem ser justificados também pelas precipitações ocorridas na região nas primeiras semanas após o plantio, nos meses de novembro e dezembro, principalmente para a espécie paineira, a qual esteve sujeita a precipitações regulares durante um período de pelo menos seis semanas após o plantio, conforme apresentado na figura 1.

Constata-se que em condições de campo as plantas das três espécies mostraram respostas similares para os quatro tratamentos (Tabela 3), onde o tratamento com $80 \%$ de biossólido manteve os maiores valores para altura, diferindo estatisticamente dos tratamentos com esterco e $20 \%$ de biossólido para as espécies farinha seca e dedaleiro e não diferindo dos demais para a paineira. Segundo Salifu e Timmer (2001), depois do plantio em campo o crescimento das raízes normalmente é lento e a absorção de nutrientes do solo é limitada, desta forma o crescimento inicial depende da translocação de reservas internas de nutrientes. Este fato pode explicar o maior crescimento em altura do tratamento $\mathrm{T} 4$, que pode ter sido favorecido pelo maior acúmulo de $\mathrm{N}$ e $\mathrm{P}$ dos tecidos, advindo da maior concentração destes nutrientes no biossólido.

A boa resposta de todos os tratamentos para sobrevivência, altura e DNS, demonstra que todos os substratos avaliados produziram mudas adequadas para plantio em campo. Pode-se afirmar que os parâmetros morfológicos atingidos pelas mudas no presente trabalho foram adequados ao plantio independente do substrato. Tendo em vista a necessidade de calibração do IQD para utilização com espécies nativas e considerando o sucesso obtido no plantio em campo, é possível afirmar que os valores mínimos de IQD verificados no presente trabalho, de 1,31 para farinha seca, 0,60 para dedaleiro e 1,35 para a paineira, seriam suficientes para atestar a qualidades de mudas dessas respectivas espécies nas condições avaliadas.

Importa ressaltar que, para validade dessas informações, devem ser consideradas as condições de solo e clima no local de plantio, bem como o recipiente utilizado para a produção das mudas. No presente estudo havia um solo bem estruturado fisicamente e as precipitações foram regulares durante 17 semanas após o plantio. Em condições de solos arenosos e ou ocorrência de estiagens, por exemplo, a sobrevivência e crescimento das mudas produzidas no presente estudo poderia ser diferente entre os tratamentos. No caso da produção em tubetes, a dinâmica de crescimento das mudas é diferente, principalmente devido a maior limitação de espaço para as raízes nesse recipiente, podendo assim variar o valor do IQD que ateste qualidade de mudas dessas mesmas espécies, quando produzidas em tubetes.

\section{CONCLUSÕES}

- biossólido tem potencial como componente de substrato para a produção de mudas de farinha seca, dedaleiro e paineira em sacos plásticos, consistindo em melhor destino final a este resíduo em comparação com a disposição em aterros sanitários.

- $\quad$ uso do biossólido pode promover maior crescimento das mudas em viveiro, bem como diminuir o peso final das mesmas, facilitando a logística de expedição para o campo. Quanto a proporção, é indicada a aplicação entre 40 a $80 \%$ de biossólido na composição do substrato, sendo mais benéficas para produção de mudas nativas proporções mais altas, próximas a $80 \%$.

- plantio em campo demonstrou boa sobrevivência e crescimento das mudas independente do substrato avaliado, indicando que todos os substratos foram capazes de produzir mudas adequadas ao plantio.

\section{AGRADECIMENTOS}

À CEDAE, à Pequena Central Hidrelétrica Santa Rosa S/A e à Coordenação de Aperfeiçoamento de Pessoal de Nível Superior (CAPES).

\section{REFERÊNCIAS}

ABREU, A. H. M.; MARZOLA, L. B.; MELO, L. A.; LELES, P. S. S.; ABEL, E. L. S.; ALONSO, J. M. Urban solid wast in the production of Lafoensia pacari seedlings. Agriambi, v. 21, n. 2, p. 83-87, 2017.

ABREU, A. H. M.; LELES, P. S. S.; MELO, L. A.; FERREIRA, D. H. A.; MONTEIRO, F. A. S. Produção de mudas e crescimento inicial em campo de Enterolobium contortisiliquum produzidas em diferentes recipientes. Floresta, v. 45, n. 1, p. 141-150, 2015. 
BASIL, G.; MAZZARINO, M. J.; ROSELLI, L.; LETOURNEAU, F. Efecto del compost de biosólidos en la producción de plantines de Austrocedrus chilensis (ciprés de la cordillera). Ciencia del Suelo, Oliveiros, n. 27, p. 49-55, 2009.

BELlOTTO, A.; VIANI, R. A. G.; NAVE, A. G.; GANDOLFI, F.; RODRIGUES, R. R. Monitoramento das áreas restauradas como ferramenta para avaliação da efetividade das ações de restauração e para redefinição metodológica. In: RODRIGUES, R. R.; BRACALION, P. H. S.; ISERNHAGEN, I. Pacto Pela Restauração da Mata Atlântica: referencial dos conceitos e ações de restauração florestal. São Paulo: ESALQ, LERF, Instituto BioAtlântica, 2009.p. 128-148.

BERTON, R. S.; NOGUEIRA, T. A. R. Uso de lodo de esgoto na agricultura. In: COSCIONE, A. R.; NOGUEIRA, T. A. R.; PIRES, A. M. M. Uso agrícola de lodo de esgoto:avaliação após a resolução no 375 do CONAMA. Botucatu: FEPAF, 2010, p. 31-50.

BETTIOL, W.; CAMARGO, O. Lodo de esgoto: Impactos ambientais na agricultura. Jaguariuna: Embrapa Meio Ambiente, 2006. 349 p.

CALDEIRA, M. V. W.; DElARMElinA, W. M.; LUBE, S. G.; GOMES, D. R.; GONÇALVES, E. O; ALVES, A. F. Biossólido na composição de substrato para a produção de mudas de Tectona grandis. Floresta, v. 42 , p. $77-84,2012$.

CALDEIRA, M. V. W.; DELARMEliNA, W. M.; LÜBE, S. G.; GOMES, D. R.; GONÇALVES, E. O.; ALVES, A. F. Biossólido na composição de substrato para a produção de mudas de Tectona grandis. Revista Floresta, Curitiba, v. 42, n. 1, p. 77-84, 2012.

CALDEIRA, M. V. W.; MARCOLIN, M.; MORAES, E.; SCHAADT, S. S. Influência do resíduo da indústria do algodão na formulação de substrato para produção de mudas de Schinus terebinthifolius Raddi, Archontophoenix alexandrae Wendl. et Drude e Archontophoenix cunninghamiana Wendl. ET Drude. Ambiência, Guarapuava, v. 3, n. 3, p. 311-323, 2007.

CALDEIRA, M. V. W.; FAVAlESSA, M.; GONÇALVES, E. O.; DELARMELINA, W. M.; SANTOS, F. E. V.; VIERA, M. Lodo de esgoto como componente de substrato para produção de mudas de Acacia mangium Wild. Comunicata Scientiae, Bom Jesus, v. 5, n. 1, p. 34-43, 2014.

CARNEIRO, J. G. A. Produção e controle de qualidade de mudas florestais. UFPR-FUPEF/Campos: UNEF, 1995, 451p.

CARVAlHO, P. E. R. Espécies Arbóreas Brasileiras: Volume 01. Brasília: Embrapa Informação Tecnologia, 2003, 1.039p.

CAVAlCANTE, A. L. G.; OLIVERIA, F. A.; PEREIRA, K. T. O.; DANTAS, R. P.; OLIVEIRA, M. K. T.; CUNHA, R. C.; SOUZA, M. W. L. Desenvolvimento de mudas de mulungu fertirrigadas com diferentes soluções nutritivas. Floresta, Curitiba, v. 46, n. 1, p. 47-55, 2016.

CONSELHO NACIONAL DO MEIO AMBIENTE (CONAMA). Resolução. Resolução no 375 de 29 de agosto de 2006. Define critérios e procedimentos para o uso agrícola de lodos de esgoto gerados em estações de tratamento de esgoto sanitário e seus produtos derivados. Diário Oficial da União, Brasília, DF, trinta de agosto 2006. Disponível em: <http://www.mma.gov.br/port/conama/res/res06/res37506.pdf> Acesso em: 04 abril 2015.

CRUZ, C. A. F.; PAIVA, H. N.; GUERRERO, C. R. A. Efeito da adubação nitrogenada na produção de mudas de sete-cascas (Samanea inopinata (Harms) Ducke). Revista Árvore, Viçosa, v. 30, n. 4, p. 537-546, 2006.

DICKSON, A.; LEAF, A.; HOSNER, J. F. Quality appraisal of white spruce and white pine seedling stock in nurseries. Forestry chronicle, v. 36, p. 10-13, 1960.

FARIA, J. C. T.; CALDEIRA, M. V. W.; DELARMELINA, W. M.; LACERDA, L. C.; GONÇALVES, E. O. Substratos a base de lodo de esgoto na produção de mudas de Senna alata. Comunicata Scientiae, v.4, p.342$351,2013$.

FAUSTINO, R.; KATO, M. T.; FLORÊNCIO, L.; GAVAZZA, S. Lodo de esgoto como substrato na produção de Senna siamea. Lam. Revista Brasileira de Engenharia Agrícola e Ambiental, Campina Grande, v. 9, p. 278-282, 2005.

FLORESTA, Curitiba, PR, v. 47, n. 2, p. 165 - 176, abr. / jun. 2017.

Cabreira, G. V. et al.

ISSN eletrônico 1982-4688

DOI: $10.5380 /$ rf.v47i1.44291 
FONSECA, E. P.; VALÉRI, S. V.; MIGLIORANZA, E.; FONSECA, N. A. N.; COUTO, L. Padrão de qualidade de mudas de Trema micrantha (L.) Blume, produzidas sob diferentes períodos de sombreamento. Revista árvore, Viçosa, v. 26, n. 4, p. 515- 523, 2002.

GOMES, J. M.; COUTO, L.; LEITE, H. G.; XAVIER, A.; GARCIA, S. L. R. Crescimento de mudas de Eucalyptus grandis em diferentes tamanhos de tubetes e fertilização N-P-K. Revista Árvore, Viçosa. v. 27, n. 2, p. 113-127, 2003.

GONÇALVES, J. L. M.; POGGIANI, F. Produção de mudas de espécies nativas: substrato, nutrição, sombreamento e fertilização. In: GONÇALVES, J. L. M.; BENEDETTI, V. (Eds.) Nutrição e fertilizaçãa florestal. Piracicaba: IPEF, 2000. p. 80-102.

INSTITUTO ESTADUAL DO AMBIENTE (INEA). Observatório Florestal Fluminense: Compromisso de restauração atualizados para o estado do Rio de Janeiro por Região hidrográfica. Instituto Estadual do Ambiente, Rio de Janeiro, 2015. Disponível em: <http://www.restauracaoflorestalrj.org/\#!off/zoom/c19az/ image lhq >. Acesso em: 14 nov 2015.

Resolução INEA no 89, de 03/06/2014. Diário Oficial do Estado do Rio de Janeiro, Rio de Janeiro, RJ, cinco de junho de 2014. Disponível em: <http://www.inea.rj.gov.br/cs/groups/public/documents/document/ zwew/mdu5/ edisp/inea0059810.pdf >. Acesso em: 14 nov 2015.

INSTITUTO NACIONAL DE METEOROLOGIA (INMET). Precipitação diária e temperatura máxima Cordeiro, RJ. Disponível em: <http://www.inmet.gov.br/html/observacoes.php?>. Acesso em 15 maio 2014.

JOSÉ, A. C.; DAVIDE, A. C.; OLIVEIRA, S. L. de. Efeito do volume do tubete, tipo e dosagem de adubo na produção de mudas de aroeira (Schinus terebinthifolia Raddi). Agrarian, Dourados, v. 2, n. 3, p. 73-86, 2009.

MAlAVOlTA, E. ABC da Adubação. 5a . ed. São Paulo: Agronômica Ceres Ltda., 1989. 292p.

ROSSA, U. B.; ANGElO, A. C.; NOGUEIRA, A. C.; BOGNOLA, I. A.; POMIANOSKI, D. J. W.; SOARES, P. R. C.; BARROS, L. T. S. Fertilizaçao de liberação lenta no crescimento de mudas de paricá em viveiro. Pesquisa Florestal Brasileira. Colombo, v. 33, n. 75, p. 227-234, 2013.

SISTEMA PARA ANÁLISES ESTATÍSTICAS E GENÉTICAS (SAEG). Versão 9.1: Fundação Arthur Bernardes - Universidade Federal de Viçosa, Viçosa, 2007.

SALIFU, K. F.; TIMMER, V. R. Nutrient retranslocation response of Picea mariana seedlings to nitrogen supply. Soil Science Society of American Journal, Sacramento, n. 65, p.905-913, 2001.

SCHEER, M. B.; CARNEIRO, C.; BRESSAN, O. A.; SANTOS, K. G. Crescimento e nutrição de mudas de Lafoensia pacari com lodo de esgoto. Floresta e Ambiente, Seropédica, v. 19, p. 55-65, 2012.

SCREMIN-DiAS, E.; KALIFE, C.; MENEGUCCI, Z. R. H.; SOUZA, P. R.. Série Rede de Sementes do Pantanal 2 - Produção de mudas de espécies florestais nativas (manual). Campo Grande: Editora UFMS. v. 1. 57p., 2006.

Secretaria de Estado do Ambiente (SEA). Diagnóstico da produção de mudas de espécies nativas no estado do Rio de Janeiro. Rio de Janeiro: SEA, 2010.

TELES, C. R.; COSTA, A. N.; GONCALVES, R. F. Produção de lodo de esgoto em lagoas de estabilização e o seu uso no cultivo de espécies florestais na região sudoeste do Brasil. Sanare, Curitiba, v.12, n. 12, p. 53-60, 1999.

TRAZZI, P. A.; CALDEIRA, M. V. W.; REIS, E. F.; SILVA, A. G. Produção de mudas de Tectona grandis em substratos formulados com biossólido. Cerne, v. 20, p. 293-302, 2014.

TRIGUEIRO, R. M.; GUERRINI, L. A. Uso de biossólidos como substratos para produção de mudas de eucalipto. Scientia Forestalis, Piracicaba, n. 64, p. 150 - 162, 2003.

VARELA, S.; MARTINEZ, A. Uso del compost de biossólidos em la formulación de sustratos para la producción industrial de plantas de Nothofagus alpina. Bosque, Valdivia, v. 34, n.3, p. 281 - 289, 2013. 